\title{
Promosi Perpustakaan Melalui Bulletin di Perpustakaan “HAMKA" SD Muhammadiyah Condongcatur: Best Practice
}

\author{
Nurrohmah Hidayah \\ Program Studi Interdiciplinary Islamic Studies, Pascasarjana Ilmu \\ Perpustakaan dan Informasi Universitas Islam Negeri Sunan Kalijaga, \\ Yogyakarta
}

\begin{abstract}
This paper aims to explain the development of promotional products in Library elementary Muhammadiyah Condongcatur, through the creation of library bulletins. In this study, the authors aim to explain the six stages in the implementation of this program: 1) analyze user needs, 2) build partnerships, 3) develop activities and resources, 4) implementation of promotion, 4) evaluation. The results of this study is a bulletin product that can be used as a library promotion tool and as an activity to increase interest in reading and writing for all school civitas. The program in this study needs to be addressed as there are many other elementary school libraries to develop promotion at the primary school level.
\end{abstract}

Keywords: School Library, Library Promotion.

\section{Pendahuluan}

Perpustakaan sekolah merupakan elemen dari sebuah pendidikan, Rahayuningsih ${ }^{1}$ menyatakan bahwa pemerintah mengakui bahwa perpustakaan sekolah adalah bagian integral dari suatu sistem pendidikan di

${ }^{1}$ Rahayuningsih, Fransisca. "Menyiapkan Pustakawan Sekolah Ideal untuk Mendukung Pelaksanaan Kurikulum 2013”. Dalam Sankakalla, Edisi 16 
sekolah. Perpustakaan merupakan jantung pendidikan di sekolah memegang andil besar dalam pengembangan ketrampilan siswa. Penyelenggaraan perpustakaan disesuaikan dengan visi dan misi sekolah. Sedangkan menurut Lasa $\mathrm{Hs}^{2}$ perpustakaan sekolah atau madrasah pada hakikatnya adalah sistem pengelolaan informasi oleh sumber daya manusia yang terdidik dalam bidang perpustakaan, dokumentasi, dan informasi. Pengelolaan dan pemanfaatan perpustakaan sekolah memerlukan sumber daya manusia yang profesional, gedung atau tata ruang yang representatif, anggaran yang memadai, sarana dan prasarana yang cukup dan koleksi yang memadai.

Menurut Suherman ${ }^{3}$, program yang dibuat oleh perpustakaan sekolah merupakan bagian yang sangat penting untuk membentuk siswa menjadi pembelajaran seumur hidup. Program yang dibuat ditunjukan untuk meningkatkan kemampuan belajar siswa, membantu mereka untuk menjadi pemikir bebas, dan problem solvers, serta membantu mereka menjadi cinta membaca. Demikian pula dengan Perpustakaan "HAMKA" SD Muhammadiyah Condongcatur. Salah satu kegiatan yang sudah berlangsung di perpustakaan "HAMKA" SD Muhammadiyah Condong Catur dalam rangka mewujudkan pembelajaran seumur hidup yaitu dengan berbagai program. Program yang sudah berjalan yaitu program literasi informasi, reading day, show and tell, pangung boneka tangan, pojok baca dan pembentukan komunitas pustakawan kecil sebagai penggerak literasi informasi sekolah.

Sebagai cara untuk memperkenalkan program dan meningkatkan minat pengunjung ke perpustakaan maka perlunya diadakan sebuah promosi perpustakaan. Promosi perpustakaan merupakan rangkaian kegiatan perpustakaan yang dirancang agar masyarakat mengetahui manfaat sebuah perpustakaan melalui koleksi, fasilitas, dan produk atau layanan yang disediakan ${ }^{4}$. Melalui kegiatan promosi diharapkan masyarakat dapat mengenal dan

${ }^{2}$ Lasa Hs. 2009. Manajemen Perpsuatakaan Sekolah. Yogyakarta: Pinus.

${ }^{3}$ Suherman. 2013. Perpustakaan Jantung Sekolah. Bandung: Literate

${ }^{4}$ Yuventia, Yuniwati. 2009. "Materi Seminar Nasional: Strategi Promosi Layanan Perpustakaan". http://yuni_yuven.blog.undip.ac.id/2009/12/14/strategi-promosi-layanan-perpustakaan/, diunduh 1 Januari 2018. 
memanfaatkan pelayanan dan fasilitas yang ada di perpustakaan.

Perpustakaan SD Muhammadiyah Condongcatur memiliki beberapa sarana promosi diantaranya brusur, pampflet, panggung boneka tangan, pojok baca, pengunaan website, sosialisasi media massa. Namun, perpustakaan "HAMKA" SD Muhammadiyah Condongcatur belum memiliki suatu produk sendiri yang dihasilkan oleh perpustakaan. Selain itu perpustakaan SD Muhammadiyah Condongcatur juga memiliki program pustakawan kecil yaitu klub yang mempunyai minat dalam kegiatan penulisan. Melihat hal tersebut bisa dijadikan potensi dalam penegmbangan sebuah promosi perpustakaan, salah satunya pembuatan bulletin sebagai salah satu media promosi dan peningkatan minat baca dan menulis siswa.

Makalah ini ditulis berdasarkan best practice penulis dalam rangka praktikum di Perpustakaan "HAMKA" SD Muhammadiyah Condongcatur. Penulis ingin memaparkan langkah-langkah dalam melakukan promosi perpustakaan melalui program bulletin. Tujuannya yaitu ingin mempromosikan perpustakaan, memperdayakan potensi yang ada di sekolah SD Muhammadiyah Condongcatur.

\section{Metode Penelitian}

Kajian ini ditulis berdasarkan best practice yang telah dilakukan pada Praktikum di Perpustakaan "HAMKA" SD Muhammadiyah Condongcatur pada tanggal 25 Oktober sampai 15 Desember 2017. Metode best practice bertujuan memaparkan langkah-langkah terbaik untuk menghasilkan hasil keluaran yang mendekati standar. Achmad Mardiansyah mengatakan bahwa yang dimaksud dengan "best practices" adalah implementasi suatu konsep/teknologi yang banyak dipakai oleh indvidual maupun organisasi. Hal menarik yang perlu diketahui adalah, best practices tidak selalu identik dengan teknologi terkini, konsep tercanggih, maupun peralatan mahal. tetapi kembali ke definisinya, sesuatu yang banyak dipakai oleh masyarakat ${ }^{5}$.

\footnotetext{
${ }^{5}$ Achmad Mardiansya, dalam https://achmadjournal.com/2006/02/10/apa-ya ng-dimaksuddengan-best-practices/ diakses pada tanggal 1 Januari 2018.
} 


\section{Kajian Pustaka}

1. Promosi Perpustakaan

Pada dasarnya promosi adalah sebuah cara dalam menginformasikan tentang layanan apa saja yang ada dalam perpustakaan agar dapat mempengaruhi masyarakat dalam mengunjungi perpustakaan. Menurut Standley dalam mustofa, tujuan promosi adalah mempengaruhi pengetahuan, sikap perilaku dari penerima, dan membujuk mereka untuk menerima, konsep pelayanan, idea tau barang yang dipromosikan ${ }^{6}$. Namun menurut Lasa Hs, promosi adalah pertukar informasi antar organisasi/ lembaga konsumen dengan tujuan utama member informasi tentang produk atau jasa yang tersedia dalam organisasi dan membujuk konsumen untuk bereaksi terhadap produk dan jasa tersebut ${ }^{7}$.

2. Pendekatan Program Buletin

Pelaksanaan program perpustakaan perlu direncanakan secara matang agar berjalan sesuai rencana. Oleh sebab itu dibutuhkan rencana induk dan pengembangan. Seperti perencanaan kurikulum, strategi pemasaran dan sebagainya. Oleh karena itu perlu tahapan dalam menjalankan suatu program.

Menurut Burmank ${ }^{8}$, beberapa pendekatan dalam melakukan promosi di perpustakaan yaitu

a. Menentukan sasaran target

Dalam menenukan target sasaran, pustakawan harus melihat beberapa kelompok yaktu karyawan, guru, orang tua dan masyarakat umum. Setiap target membutuhkan strategi promosi yang berbeda. Hal ini penting mengingat bahwa promosi tidak hanya untuk siswa, melainkan untuk berbagai lapisan masyarakat. Hal ini mengingat biasanya pustakawan hanya mefokuskan promosi hanya ke siswa,

\footnotetext{
${ }^{6}$ Badollahi, Mustofa, 2011, Promosi Jasa Perpustakaan, Jakarta: Universitas Terbuka, hlm 20

${ }^{7}$ Lasa, Hs, Kamus Kepustakawanan Indonesia. Yogyakarta : Pustaka Book Publiser, hlm 290.

${ }^{8}$ Read Burkman, Amy (Nov / Dec 2004). A Practical Approach to Marketing the School Library (Access requires login). Library Media Connection; 23(3), 42-43.
} 
namun mengesampingkan pemustaka yang lainnya.

b. Program pemasaran

Pustakawan harus bisa mengambil beberapa pendekatan dalam melakukan pemasaran program, melakukan survai target kebutuhan dan bekerja sama dengan pustakawan lainnya. Kendala waktu membuat kebanyakan pustakawan melakukan kegiatan promosi sendirian.

c. Petugas Admistrator.

Cara efektif untuk membuktikan adanya afektivitas perpustakaan yaitu dengan cara mengumpulakan data tentang penggunaan siswa dan guru yang datang ke perpustakaan setiap semester sekali. Serahkan data ke petugas administrasi tetang data penggunaan perpustakaan seperti : bahan yang diedarkan, jumlah siswa yang mengunakan perpustakaan dan jumlah kelas yang mengunakan perpustakaan.

d. Orang tua

Perpustakaan sekolah harus bisa melibatkan orang tua dalam proses pemasaran. Hubungan pustakawan sekolah dan orang tua biasanya berkembang dari peluang bantuan berbentuk materi perpustakaan. Mempromosikan kepada orang tua harus mencakup seluruh keluarga. Perlu program khusus yang memungkinkan orang tua dan anak bersama sama mengikuti program di sekolah.

e. Guru

Guru adalah mitra berharga dalam perpustakaan sekolah. Dibutuhkan guru dan guru pustakawan bekerja sama untuk menciptakan lingkungan belajar yang kondusif. Hal ini menjadi sebuah tantangan untuk sebagian besar pustakawan membawa guru datang dan menyukai perpustakaan.

f. Siswa

Siswa merupakan target termudah dalam melakukan promosi perpustakaan. Pustakawan harus mempunyai ide yang kreatif agar siswa ingin pergi ke perpustakaan. Selain itu perpustakaan sangat penting 
unuk memiliki kontens yang melibatkan siswa yang tidak hanya membaca. Sehingga dapat melatih kreativitas siswa.

g. Komunitas

Komunitas diperlukan untuk membangun pemasaran. Menciptakan kerja sama antara perpustakaan sekolah menegah atas dan bawah. Selain itu perpustakaan harus mampu membangun komunitas di masyarakat luas.

h. Evaluasi Pemasaran

Tekniknya adalah memonitor penggunaan perpustakaan Alat evaluatif pemasaran dapat berupa survei. Survei orang tua, guru, dan siswa dan lainnya.

3. Proses Pelakasanaan Program

Pelaksanaan sebuah program promosi pastinya membutuhkan sebuah perencanaan yang matang. Dibutuhkan langkah-langkah untuk keberhasilan program. Menurut Debora ${ }^{9}$, beberapa langkah dalam melaksanakan program acara di perpustakan antara lain

a. Mengembangkan strategi agar program berjalan sukses

Hal ini harus memperhatikan beberapa hal seperti a) memastikan tujuan, waktu dan biaya b) sasaran pengguna c) dukungan pihak lain d) perancanaan tiga bulan sebelumnya.

b. Buat daftar periksa

Daftar periksa menyediakan panduan langkah-demi-langkah untuk mengatur dan melaksanakan acara khusus.

c. Anggaran

Tujuannya adalah untuk menyediakan perencana . Anggaran harus spesifik, dan termasuk peluang pendapatan

d. Pertimbangkan logistik

Dengan banyaknya aktivitas yang terjadi bersamaan, ada banyak detail

${ }^{9}$ Read Meskauskas, Debora. Planning Special Events: Blueprint For Success. Friends \& Foundations of California Libraries. 
yang harus diperiksa.

e. Rencanakan publisitas

Mempromosikan sebuah acara khusus membuat pemikiran kreatif seimbang dengan kepraktisan.

f. Evaluasi acara

Luangkan waktu untuk mengevaluasi tepat setelah acara berlangsung sementara rinciannya masih segar.

Sedangkan menurut Lamp dan Larry ${ }^{10}$, menyebutkan beberapa langkah dalam melaksanakan kegiatan promosi di perpustakaan sekolah yaitu

a. Menganalisis kebutuhan pengguna di perpustakaan tersebut sesuai pendekatan yang digunakan.

b. Membangun kemitraan. Meminta orang lain terlibat dengan promosi. Pertimbangkan koneksi kurikulum. Bergabung dengan anggota komunitas pembelajaran lainnya dan mencari komunitas yang memiliki komitmen.

c. Mengembangan kegiatan dan sumber daya. Membuat sebuah timeline akan melakukan apa, siapa yang akan melaksanakan, dan menyiapkan materi yang diperlukan.

d. Penerapan promosi, Melakukan promosi dan menyebarkan produk yang dihasilkan serta melakukan survai.

e. Evaluasi. Tujuan evaluasi yaitu mempertimbangkan kefektifan program.

\section{Analisis Dan Pembahasan}

\section{Gambaran Umum Perpustakaan "HAMKA" SD Muhammadiyah Codong- catur}

Perpustakaan "HAMKA" SD Muhammadiyah Condongcatur merupakan perpustakaan sekolah yang berada di Jl. Ringroad Utara, Gorongan,

${ }^{10}$ Lamb and Larry Johnson, 2013. Advocacy: Promotion: Public Relations, Advertising and Marketing . http://eduscapes.com/sms/advocacy/promotion.html. Diakses pad 9 Januari 2018 
Condongcatur. Perpustakaan "HAMKA" SD Muhammadiyah Condongcatur berdiri seiring dengan berdirinya SD Muhammadiyah Condongcatur, yakni pada tahun 1998. Perpustakaan "HAMKA" SD Muhammadiyah Condongcatur memiliki visi mewujudkan perpustakaan sekolah sebagai pendukung proses kegiatan belajar mengajar di SD Muhammadiyah Condongcatur. Sedangkan Misinya diantaranya yaitu, 1) Menjadikan perpustakaan sebagai tempat bagi warga sekolah (kepala sekolah, guru, murid, dan karyawan) untuk memperdalam informasi/ pengetahuan dari berbagai jenis bahan pustaka dengan membaca, mengamati, mencermati, dan mendengarkan, 2) Memberikan pelayanan prioma dengan senyum, salam, sapa, sopan dan santun, 3) Menumbuhkembangkan minat baca sebagai budaya warga sekolah, 4) meningkatkan kerjasama dengan perpustakaan dan pusat informasi lain, 5) Rekreasi intelektual bagi warga SD Muhammadiyah Condongcatur.

Perpustakaan "HAMKA" SD Muhammadiayah Condongcatur memiliki berbagai program kerja. Program kerja ini bertujuan untuk mewujudkan visi dan misi yang ingin dicapai. Program yang telah berjalan diantaranya pustakawan kecil, pangung boneka tangan, pojok leterasi, gazebo literasi, reading day.

\section{Promosi Perpustakaan melalui Bulletin Perpustakaan}

Perpustakaan "HAMKA" SD Muhammadiyah Condongcatur sleman Yogyakarta, memiliki beberapa program koleksi yang sudah berjalan antara lain yaitu pamflet,brosur, panggung boneka tangan. Pengembangan promosi perpustakaan selalu dikembangkan oleh perpustakaan, dalam rangka menumbuhkan minat baca, selain itu perpustakaan HAMKA memiliki visi untuk meningkatkan budaya menulis. Oleh karena itu dibutuhkan promosi untuk mewujudkan visi tersebut. Oleh karena itu, dalam program PPL ini penulis mencoba mengenalkan program promosi baru yaitu bulletin.

Tahapan- tahapan pelaksanaan program promosi perpustakaan melalui bulletin di Pepustkaan "HAMKA" SD Muhammadiyah Condongcatur, 
sudah melalui tahap-tahap yang dikemukakan oleh Terry dan Lammp ${ }^{11}$, Disebutkan langkah pertama dalam menyusun program perpustakaan yaitu menganalisis kebutuhan pengguna di perpustakaan tersebut sesuai pendekatan yang digunakan. Perpustakaan "HAMKA" SD Muhammadiyah Condongcatur, meliliki beberapa target sasaran promosi meliputi siswa, guru, karyawan dan orang tua. Saat ini Perpustakaan "HAMKA" SD Muhammadiyah Condongcatur telah mempunyai produk promosi yang sudah ada yaitu brosur, pampflet, pojok baca, panggung boneka tangan. Selama penulis Praktikum di SD Muhammadiyah Condongcatur, penulis belum mengamati adanya produk yang melibatkan siswa dalam proses pengerjaannya, selain itu banyaknya potensi anak yang ada, sehingga penulis ingin membuat program pembuatan promosi.

Tahapan yang kedua, yaitu membangun kemitraan. Perpustakaan "HAMKA" SD Muhammadiyah Condongcatur memiliki program pustakawan kecil, Pustakawan kecil yaitu klub perpustakaan yang terdiri dari siswa yang memiliki ketertarikan dengan dunia buku dan tulis menulis. Melihat potensi yang ada, penulis membangun mitra dengan pustakawan kecil tersebut dalam proses pembuatan bulletin ini. Pustakawan kecil dilibatkan dalam proses pembuatan, mulai dari pemilihan judul bulletin, pengumpulan materi, dan pengeditan tulisan. Selain melibatkan pustakawan dan pustakawan kecil, bulletin ini juga melibatkan siswa, guru, dan karyawan dalam proses pengumpulan karya. Sehingga banyak pendekatan yang dibangun dalam pembuatan bulletin ini, sehingga bulletin ini dapat bermanfaat dikalangan luas.

Tahap ketiga yaitu mengembangan kegiatan dan sumber daya. Proses ini meliputi kegiatan pengembangan kegiatan, pembuatan susuanan redaksi, penentuan judul bulletin, pembuatan timeline kegiatan, anggaran yang dibutuhkan dan menyiapkan materi yang diperlukan. Selain itu, dalam proses ini pustakawan membuat pedoman penulisan serta pembuatan proposal kegiatan agar disetujui oleh kepala sekolah, Setelah disetujui oleh perpustakaan dan melakukan rapat kordinasi, pustakawan kecil

\footnotetext{
${ }^{11}$ Ibid.
} 
mensosialisasikan kegiatan ini, dengan memasang pamflet. Tujuan pamfhlet ini yaitu untuk memberitahukan kepada siswa, guru dan karyawan agar mengumpulkan karya terbaik untuk diterbitkan pada bulletin. Beberapa karya yang terkumpul kemudian diseleksi yang cocok untuk diterbitkan dan tidak. Setelah itu pengatur layar bulletin dan dicetak.

Tahap keempat yaitu penerapan promosi, Hasil dari pelaksanaan program adalah terwujudnya program promosi perpustakaan. Hasil dari produk bulletin ini disebarkan ke seluruh warga sekolah maupun masyarakat. Bulletin ini dapat diakses di perpustakaan, kelas, ruang guru dan ruang kepala sekolah.

Setelah melakukan promosi kemudian di evaluasi. Setiap program perpustakaan yang dilakukan perpustakaan pastinya dilakukan sebuah evaluasi. Karena pihak perpustakaan baru pertama kali melakukan program ini maka perpustakaan perlu mengadakan evaluasi supaya dapat dijadikan sebuah perbaikan untuk program selanjutnya. Hasil evaluasi dapat disimpulkan bahwa masih banyak kata dan tanggal yang salah, penyebutan gelar masih banyak yang salah, sumber rujukan masih belum dicantumkan, waktu pelaksanaan masih kurang efektif. Dari hasil evaluasi ini diharapkan, kedepan kegiatan pembuatan bulletin bisa berjalan secara rutin dan dapat lebih baik dari segi konten maupun secara teknis. Hasil pelaksanaan program ini nantinya dapat dijadikan acuan untuk pembuatan program selanjutnya.

\section{Dampak Pelaksanaan Program}

Program kegiatan pembuatan bulletin memiliki dampak positif bagi pustakawan, pustakawan kecil dan sekolah. Bagi perpustakaan, program ini dapat mewujudkan visi perpustakaan untuk meningkatkan minat baca dan menulis, serta sebagai media promosi. Bagi pustakawan kecil, program ini dapat mengasah kreativitas siswa, melatih bakat menulis, sebagai media literasi informasi. 


\section{Kesimpulan}

Berdasarkan uraian diatas dapat disimpulkan bahwa program pembuatan bulletin layak untuk di terapkan untuk kegiatan promosi perpustakaan. Program pembuatan Bulletin di perpustakaan "HAMKA" SD Muhammadiyah condongcatur telah berhasil melalui tahapan-tahapan pelaksanaan program dari proses perencanaan atau analisis kebutuhan sampai evaluasi. Selain menjadi sarana promosi perpustakaan, program bulletin juga mampu mengasah ketrampilan siswa, guru, pustakawan maupun karyawan untuk berkreasi dan berlatih menulis. Sehingga diharapkan program ini terus belanjut dan melakukan perbaikan perbaikan setelah adanya evaluasi.

\section{Daftar Pustaka}

Rahayuningsih, Fransisca. "Menyiapkan Pustakawan Sekolah Ideal untuk Mendukung Pelaksanaan Kurikulum 2013”. Dalam Sankakalla, Edisi 16

Lasa Hs. 2009. Manajemen Perpsuatakaan Sekolah. Yogyakarta: Pinus.

Suherman. 2013. Perpustakaan Jantung Sekolah. Bandung: Literate

Yuventia, Yuniwati. 2009. “Materi Seminar Nasional: Strategi Promosi Layanan Perpustakaan”. http://yuni_yuven.blog.undip.ac.id/2009/12/14/ strategi-promosi-layanan-perpustakaan/, diunduh 1 Januari 2018.

Achmad Mardiansya, dalam https://achmadjournal.com/2006/02/10/apa-ya ng-dimaksud-dengan-best-practices/ diakses pada tanggal Januari 2018.

Badollahi, Mustofa, 2011, Promosi Jasa Perpustakaan, Jakarta: Universitas Terbuka, hlm 20

Lasa, Hs, Kamus Kepustakawanan Indonesia.Yogyakarta : Pustaka Book Publiser, hlm 290.

Read Burkman, Amy (Nov / Dec 2004). A Practical Approach to Marketing the School Library (Access requires login). Library Media Connection; 23(3), 42-43 
Read Meskauskas, Debora. Planning Special Events: Blueprint For Success. Friends \& Foundations of California Libraries

Lamb and Larry Johnson, 2013. Advocacy: Promotion: Public Relations, Advertising and Marketing . http://eduscapes.com/sms/advocacy/ promotion.html. Diakses pad 9 Januari 2018 